\title{
Enhancing the Library and Information Management curriculum through Reusable Learning Objects
}

\author{
Margaret Kendall \\ Manchester Metropolitan University \\ Centre for Learning and Teaching \\ St Augustine's, Manchester \\ M15 6BY \\ m.a.kendall@mmu.ac.uk \\ Nicola Wakefield \\ Information Services Division \\ University of Salford \\ Salford \\ M5 4WT \\ n.wakefield@salford.ac.uk \\ Rachel Delbridge \\ Manchester Metropolitan University \\ Information and Communications \\ Geoffrey Manton Building, Manchester \\ M15 6LL \\ r.delbridge@mmu.ac.uk
}

\begin{abstract}
Increased communication with practitioners and improved curriculum coverage of specialist sectors have been identified as priorities for Library and Information Management (LIM) educators. This paper discusses a project exploring the potential for reusable learning objects (RLOs) as a response. Ten reusable learning objects on law librarianship, one of which was then repurposed for the health information sector, were created in consultation with practitioners and their use evaluated using an action research strategy. The issues which arose during the creation and deployment of the RLOs are discussed, including granularity, interoperability, levels of learning activity and impact. Positive feedback from both students and practitioners indicates the value of the approach.
\end{abstract}

\section{Keywords}

Reusable learning objects, online learning, e-learning, blended learning, librarianship, law

\section{Introduction}


At Manchester Metropolitan University (MMU) and the University of Northumbria (UN), resource constraints prevent the running of specialist options on law librarianship despite staff research interests in the field. Creating Reusable Learning Objects (RLOs) was identified as a way of enhancing the curriculum, enabling the team to share expertise for creating subject content, designing and developing the materials.

It was also seen as a means of strengthening links between the Departments and law librarians, to quality assure the RLOs and build opportunities for offering short courses for practitioners new to law librarianship without them having to travel to London, where most training opportunities are currently available.

Funding for a project to create RLOs on law librarianship, developed for students in partnership with practitioners, was obtained from the Development Fund of the HEAcademy Information and Computer Science (ICS) Subject Centre. As well as creating the RLOs, the project aimed to illustrate how they could be repurposed for teaching students at different levels, to provide examples with potential for repurposing for other specific ICS sectors and to identify issues for consideration by anyone seeking to carry out similar work with other vocations.

This paper discusses the background and context to the initiative, the process undertaken by the team in designing, creating and evaluating the RLOs using action research methods, their use in teaching first year undergraduate and postgraduate students, and the issues which arose during their creation and deployment.

\section{Background and context}

Over the last 10 to 15 years, pressures on the Library and Information Management (LIM) curriculum as a result of rapid economic, political and technological change have led to reductions in teaching about specific information environments. Following the Quality Assurance Agency for Higher Education (2002) subject review, the Higher Education Funding Council for England (2003) identified priorities for all subjects to improve "co-operation in development of digital resources" and for librarianship and information management to achieve "a closer relationship between the curriculum and requirements of professional training".

McTavish and Ray (1999) surveyed legal information practitioners in four sector categories to identify the range of skills vital to their roles. Whilst the respondents considered that core teaching in LIM Departments was transferable to their context, they identified a need for more coverage of the work of special libraries and "increased communication between professionals in practice and the various universities who offer information degree and masters programmes". Brown and Stephens (2004) found that only $25 \%$ of LIM Departments responding to their survey offered a postgraduate module on legal materials, although the option would have been appreciated by 61 (60\%) of their student respondents.

There is considerable interest in the use of e-learning within the law librarianship sector. Pettit (2006) draws from a survey of academic law librarians' involvement with e-learning conducted via the JISCmail list LIS-LAW to illustrate the extent of current activity and highlight the importance of such initiatives: "The advent of the electronic environment could sever the long-standing interdependence of legal practitioners and librarians. One way to prevent this happening is for us to develop, be identified as having, and actively promote, competencies for the e-learning environment".

For university law librarians, e-learning is a solution to high ratios of students to librarians, increased curriculum priorities on practical legal research and the predominance of electronic resources. An example is the online guide at the University of the West of England which includes interactive floor guides, audio 
enabled database demonstrations and video clips (Crossley and Tylee, 2005). The Internet for Lawyers tutorial (Pettit, 2007) written by the University of Bristol Law Librarian includes a selection of recommended resources for lawyers and gives guidance on seeking and evaluating information on the Internet. The LawPaths project provides a database of information skills materials which are freely available for librarians to use with law students (Carter and Gladin, 2005).

Students of library and information management new to the field of legal information were the target audience for this project. Liaison with law librarian practitioners was considered essential in order to gain their interest and support and to create learning resources which would enhance the employability of students of librarianship and information management. Team meetings were held to initiate and review the two phases of the project, supported by regular online communication.

\section{Phase One: Creating the RLOs}

\subsection{Levels of granularity}

At the start of the project, the team consulted the literature on the design of reusable learning objects (e.g. Littlejohn, 2003; Casey and McAlpine, n.d.) and investigated and shared examples of reusable learning objects through collections available, including Wisc-Online (2007) and MERLOT (Multimedia Educational Resource for Learning and Online Teaching, 2007).

There are differences of opinion about the optimum size of RLOs, known as granularity. As explained by Duncan (2003), some argue in favour of the learning objects being as small as possible (high granularity), e.g. a single diagram or image, to maximise opportunities for reuse and others for the need for resources to be large enough to have sufficient educational value (low granularity). Since the aim was to provide specialist content for use within a variety of learning contexts and at different levels, the team agreed that each RLO needed to be small enough to enable such reuse but large enough to provide a coherent learning experience in its own right. The UCEL (Universities' Collaboration in eLearning) definition of a RLO was identified as being suitable for the purposes of the project "an interactive web-based resource based on a single learning objective and comprising a stand-alone collection of 4 components: presentation, activity, assessment and links" (Leeder, n.d.).

\subsection{Pedagogic rationale}

As the target audience for the RLOs was students new to the field, they needed to be within the cognitive domain of educational activity according to Bloom (Clark, 1999), with the emphasis on knowledge and comprehension. Online learning was identified as an appropriate means of enabling students to test their memory and understanding through self-tests and apply their skills through practical exercises. More complex activities would need to be developed through use of the RLOs either within a blended learning context or a more extensive online course according to the students' level of study.

\subsection{Topic selection}

The team began by sharing existing resources created in their respective universities. Practitioners were involved in suggesting suitable topics, through the team members' own networks, the BIALL (British and Irish Association of Legal Librarians, 2007) annual conference and the Manchester Legal Information Group. 
The project was also informed by the work of the large scale Phase 5 FDTL project known as LIMES (Library and Information Management Employability Skills, 2007). Their survey of employers, employment agencies and professional associations included skills requirements for law librarians.

The team agreed the need for some of the RLOs to focus on print resources and include downloadable exercises to facilitate skills acquisition. Richards' (2005) survey of 71 trainee lawyers reveals weaknesses in their knowledge of hard copy material and the potential usefulness of particular sources, such as Halsbury's statutes. Student librarians need awareness of the range of formats, particularly since the expensive online tools they may enjoy if their university library supports a Law School may not be available in smaller law firms.

A long list of around 100 possible RLOs on law librarianship was identified, following consultation with legal librarian practitioners. These were grouped under 23 headings, from which 10 were selected as illustrating the range of possible topics and reflecting the priorities for development identified through consultation.

RLO1: The English court structure

RLO2: Introduction to legislation

RLO3: Case law

RLO4: Law reports

RLO5: Finding case citations electronically

RLO6: Halsbury's Laws of England

RLO7: Using Halsbury's statutes

RLO8: Using Current Law Case Citator

RLO9: Legal dictionaries

RL010: Introduction to Knowledge Management

The learning objective for RLO3 was simply to introduce case law and citation, the topic was developed further in RLO4, RLO5 and RLO8. This would enable their use to be combined, but cross references between them were not made to increase opportunities for reusability. At a later stage, RLO 9 was selected as an example for repurposing as Medical dictionaries, following consultation with staff in a medical library.

\subsection{Interoperability}

As Campbell (2003) states, "there is little value in developing granular, reusable learning objects if they are tied to a single proprietary delivery system" thus preventing reuse within different virtual learning environments (VLEs) and incorporation of features such as tracking student progress and summative assessment. The RLOs were developed at Manchester Metropolitan University using Coursegenie (2006) which produces content packages for delivery in a variety of formats. This enabled the 11 RLOs to be made available from the HE Academy-ICS web site, and downloaded in a variety of different versions to enable tutors a choice according to their needs from: zipped normal or WebCT HTML pages, Blackboard, WebCT IMS, LRN IMS or Scorm v 1.2 content packages.

\section{Phase Two: Designing and reviewing the RLOs}

For quality assurance purposes, several cycles of action research activity were undertaken in order to gain feedback, identify weaknesses and make improvements. 
1. The research associate created the content for the $10 \mathrm{RLOs}$ and made the text available for comment by members of the team via the project's WebCT discussion area.

2. The 10 RLOs were created and uploaded into WebCT for review by the team after which several decisions about the desired look and feel were made e.g. avoiding use of pop-ups where the information is essential rather than for clarification.

3. A feedback survey was piloted and further comments were gathered from members of the team plus 2 willing practitioner contacts.

4. Some amendments were made before the RLOs were used as integral parts of taught units on the undergraduate and postgraduate programmes at MMU.

5. Comments and suggestions from the students were used to revise the modules before they were made available for review by students at Northumbria University and the practitioners from law firms.

For example, at cycle 1, it was suggested that a diagram would help the students to understand the English Court Structure in RLO1. The research associate designed an interactive diagram about which some members of the team expressed concern at cycle 2. At cycle 3, one practitioner suggested that a link to a diagram on an external authoritative web site, Her Majesty's Courts Service (2006), be used instead. At cycle 4, some redesign of the RLO was made so that students were asked to find answers to multiple choice questions using the web site as the source of information. Postgraduate students at MMU completed and commented on RLO1 using the feedback survey. At cycle 5, further adjustments were made with positive results from the practitioners and postgraduate students (pgs) from the UN. See Table 1.

\begin{tabular}{|l|l|l|l|l|l|}
\hline Cycle 4: MMU pgs (9) & SA & A & A? & D & SD \\
\hline Aim of the module is clear & & 8 & 1 & & \\
\hline Easy to read and absorb information & & 8 & 1 & & \\
\hline Style of writing makes topic interesting & & 3 & 5 & 1 & \\
\hline Diagrams or pictures are helpful & & 6 & 1 & 2 & \\
\hline Cycle 5: Practitioners (7) \& UN pgs (3) & & & & & \\
\hline Aim of the module is clear & 7 & 3 & & & \\
\hline Easy to read and absorb information & 7 & 1 & 2 & & \\
\hline Style of writing makes topic interesting & 3 & 6 & 1 & & \\
\hline Diagrams or pictures are helpful & 6 & 1 & 1 & 2 & \\
\hline $\begin{array}{l}\text { SA = strongly agree A= Agree A? = agree with reservations D = disagree } \\
\text { SD = strongly disagree }\end{array}$
\end{tabular}

Table 1: Quantitative feedback on presentation of RLO1

At the end of each section of the survey, respondents were asked to comment on their responses, and these comments were most valuable in identifying changes to be made. For example, two of the MMU postgraduate students made the following comments:

"Some pages literally have too much text on them in order to absorb the information effectively" 
"Not clear about how to get back to home page for this tutorial - didn't make note that you need to click on X to escape from HMCS website so got lost"

Comments from the practitioners showed that the changes made had been successful, for example, one commented that "Overall, the presentation of the module is very clear and very good. The user can proceed at their own pace depending on how much they already know." Another commented that "The use of diagrams is very good in this module as it should help the student to retain the information by planting a clear visual image."

At cycle 4, the comments disagreeing with the helpfulness of the diagram related to navigation. Further guidance was provided in the revised version and no-one commented on having any problems. Although two people still disagreed with the helpfulness of the diagram at cycle 5 , their comments did not recommend that its use be discontinued:

"We use this diagram in our training sessions and find that we have to split the court up as we talk about them or the facts about each court all blur into one."

"All clear and easy to follow as an introduction to the court system. Links to a useful and relevant website, although main diagram on this website is not clear on routes individual cases might take through the court system."

\section{Putting the RLOs into practice}

The RLOs were used in two quite different ways with students at different levels at MMU.

Forty one postgraduate students on the MA Library and Information Management and MSc Information Management degrees were given a lecture on electronic copyright, which included discussion of ways in which creators of electronic resources are reaching agreement about sharing and re-use of materials. This was followed by a one hour lab session introducing the concept of "reusable learning objects" and using the modules as an example. The students worked in twos or threes on RLO1 and RLO2, and were then introduced to web sites providing further detail or examples of reusable learning objects including LawPaths (2007), UCEL (2007), National Learning Network (2007), MERLOT (2007) and Jorum (2007). Their views on learning online were mainly positive, for example, see Table 2.

\begin{tabular}{|l|l|l|l|l|l|}
\hline & SA & A & A? & D & SD \\
\hline The module helped me concentrate on the topic & 1 & 11 & 4 & 1 & \\
\hline I am likely to remember what I've learnt & & 7 & 7 & 3 & \\
\hline I can now do what the module set out to teach me & & 7 & 9 & 1 & \\
\hline
\end{tabular}

Table 2: Postgraduate student experiences of RLO2

Several explained their reservations making comments similar to these "If I'm actually searching for particular information I would most likely remember it" and "if I did need to know this information in future I could come back to the tutorial". Some of the points raised in disagreement about the terminology were addressed when the RLOs were revised prior to review by the practitioners.

Eighteen undergraduate students in the first year of the BA Information and Library Management degree at MMU completed RLOs 3, 4 and 5, as part of a two hour session aiming to give them an insight into the roles of legal information professionals, an introduction to case law and how it is recorded and practical experience in finding information about cases. 
A combination of approaches was used. Learning as achieving understanding of the role of the legal information professional was introduced through an individual exercise in which they were asked to visit the Careers section of the BIALL web site (British and Irish Association of Law Librarians, 2006), find out about the different contexts in which legal information professionals work and prepare questions for the Law Librarian about her experiences both in a law firm and in the University Library. After the question and answer session, the students completed RLO3 in pairs, followed by a group discussion of the examples of cases they had identified from their own experience and from consulting newspaper web sites. The students were then divided into two groups. One group worked in pairs on RLO 4 and at the appropriate point were taken to use the hard copies of the law reports in the library to carry out the exercise. The other group worked through RLO 5. After the 2 groups had swapped over to complete the work of both RLOs, a final plenary session encouraged reflection on the learning experience.

Combining e-learning activities with face to face discussions and practical activities in the library created a "buzz" amongst the students. They enjoyed working in pairs and small groups, outside of the usual classroom, and appreciated the opportunity to ask questions in a less formal way.

Fourteen feedback sheets for each RLO were completed. The students were in agreement that the modules were clearly presented as a whole and that it was clear what to do in the activities and self-assessments. One said "Really helpful, made me think not just read" and another was more specific "Looking at case studies helped my understanding of civil and criminal cases". Their views on learning online were positive, for example, see Table 3.

\begin{tabular}{|l|l|l|l|l|l|}
\hline & SA & A & A? & D & SD \\
\hline The module helped me concentrate on the topic & 3 & 10 & 1 & & \\
\hline I am likely to remember what l've learnt & 1 & 10 & 1 & 2 & \\
\hline I can now do what the module set out to teach me & 2 & 8 & 2 & 2 & \\
\hline
\end{tabular}

Table 3: Undergraduate student experiences of RLO3

\section{Conclusions}

The process of consultation was successful in identifying and creating a selection of RLOs for use with students in Higher Education at different levels and could be replicated for other vocational contexts. The RLOs were well received by the students, most of whom found that the use of online learning helped their concentration, skills development and memory.

The practitioners' comments and suggestions for additional resources were very helpful in preparing the final versions of the RLOs. However, some of the comments showed that trainers in the workplace expected more detailed content and coverage, although the concept of RLOs with potential for aggregation had been explained and the long list circulated. Given the low granularity, the RLOs could be made available to students for independent learning. Each is on a specific topic and requires around 15-30 minutes of study time. However, as it was only possible to create a small number as examples, they only cover a fraction of the information which would be needed for a law librarianship unit on a degree programme. The main benefits are likely to be derived from integration of the learning objects into a longer blended learning programme, including some face to face delivery and hands-on activities of printed sources. 
They have potential for reuse as part of teaching other related subjects on a Library and Information Management programme e.g. as an example of subject-specific training in a management unit or for teaching about learning technology. Some of the RLOs have wider applicability, e.g. RLO1 and 2 are relevant to any programme of study involving an understanding of the English legal system (including computer science) and RLOs 4-9 are relevant for students on law degrees. As illustrated by the adaptation of RLO 9 for health information, there is also potential for repurposing RLOs for other information service contexts.

The RLOs are available from the HE Academy- ICS (2007) web site. Further feedback case studies of their use in other institutions will be welcomed by the authors.

\section{References}

British and Irish Association of Law Librarians, (2007) http://www.biall.org.uk/ (accessed $1^{\text {st }}$ Feb 2007)

British and Irish Association of Law Librarians, (2006) Careers. British and Irish Association of Law Librarians.

http://www.biall.org.uk/Home.asp?id=h27\&h999=a20bdspa6bhida7bhida28bhida2bhi da3bdspa19bhida5bhida26bhida8bhida9bdspa (accessed $1^{\text {st }}$ Feb 2007)

Brown, R. and Stephens, D., (2004) Law library careers: improving the transition to legal information work. Legal information management. 4 (1) pp.19-22

Campbell, L.M. (2003) Engaging with the learning object economy. In Reusing online resources: a sustainable approach to e-learning, edited by Littlejohn, A. Kogan Page, London

Carter, S. and Gladin, L., (2005) Lawpaths as a tool for enhancing pedagogy. The Higher Education Academy UK Centre for Legal Education.

http://www.ukcle.ac.uk/resources/biall/carter.html (accessed 1st Feb 2007)

Casey, J. and McAlpine, M. (no date) Writing and using reusable educational materials: a beginner's guide. University of Glasgow.

http://www.gla.ac.uk/rcc/staff/mhairi/index.html (accessed 1st Feb 2007)

Clark, D., (1999) Bloom's taxonomy.

http://www.nwlink.com/ donclark/hrd/bloom.html (accessed 1st Feb 2007)

Coursegenie, (2006) http://www.horizonwimba.com/info.htm (accessed 1st Feb 2007)

Crossley, J. and Tylee, C., (2005) Developing an online interactive guide for law students. Legal information management. 5 (4) pp.232-235 
Duncan, C., (2003) Granularisation. In Reusing online resources: a sustainable approach to e-learning, edited by Littlejohn, A. Kogan Page, London

Her Majesty's Court Service, (2006) The Court Structure of Her Majesty's Courts Service (HMCS). Her Majesty's Court Service. http://www.hmcourtsservice.gov.uk/aboutus/structure/index.htm (accessed 1st Feb 2007)

HE Academy-ICS (2007) Reusable learning objects http://www.ics.heacademy.ac.uk/resources/rlos/index.php (accessed $1^{\text {st }}$ Feb 2007)

Higher Education Funding Council for England, (2003) Invitation to bid for funds under FDTL5. Higher Education Funding Council for England. http://www.hefce.ac.uk/pubs/HEFCE/2003/03_46/03_46.doc (accessed $1^{\text {st }}$ Feb 2007)

Jorum, (2007) http://www.jorum.ac.uk (accessed $1^{\text {st }}$ Feb 2007)

Lawpaths, (2007) http://library.kent.ac.uk/library/lawpaths (accessed 1st Feb 2007)

Leeder, D., (no date), Reusable learning objects for health professional education, Universities' Collaboration in eLearning.

http://www.ucel.ac.uk/documents/docs/content_counts.ppt (accessed $1^{\text {st }}$ Feb 2007)

Library and Information Management Employability Skills, (2007)

http://www.ics.heacademy.ac.uk/limes/CONTENT/index.htm (accessed $1^{\text {st }}$ Feb 2007)

Littlejohn, A. (ed.), (2003) Reusing online resources: a sustainable approach to elearning. Kogan Page, London

McTavish, S. and Ray, K., (1999) Law and order: trends in legal information provision. Sweet and Maxwell, London

Multimedia Educational Resource for Learning and Online Teaching, (2007) http://www.merlot.org/Home.po (accessed $1^{\text {st }}$ Feb 2007)

National Learning Network, (2007) http://www.nln.ac.uk (accessed $1^{\text {st }}$ Feb 2007)

Pettit, S., (2007) Internet for Lawyers. intute: virtual training suite. http://www.vts.intute.ac.uk/he/tutorial/lawyers (accessed $1^{\mathrm{st}}$ Feb 2007)

Pettit, S., (2006) E-learning and virtual learning environments. In BIALL Handbook of legal information management, edited by Worley, L. Ashgate, Aldershot

Quality Assurance Agency for Higher Education, (2002) Subject Overview Report 2000 to 2001 QO6/2001 Librarianship and information management. Quality 
Assurance Agency for Higher Education.

http://www.qaa.ac.uk/reviews/reports/subjectlevel/qo6_01_textonly.htm

Richards, M., (2005) Bridging the gap between academic and practical legal research training and the role for the information professional. MA dissertation, Manchester Metropolitan University.

Universities' Collaboration in eLearning, (2007) http://www.ucel.ac.uk (accessed $1^{\text {st }}$ Feb 2007)

Wisc-Online, (2007) http://www.wisc-online.com (accessed $1^{\text {st }}$ Feb 2007) 